\title{
Significance and Problems of Two-Child Policy
}

\author{
Jinguo Wang \\ Department of Urology \\ The First Hospital of Jilin University \\ Changchun, China \\ wangjinguolily@163.com
}

\author{
Corresponding author: Na Wang* \\ Department of Anesthesiology \\ The First Hospital of Jilin University \\ Changchun, China \\ wangna080613@163.com
}

\begin{abstract}
The two-child policy is necessary now in China. According to the literature and the current status of Chinese population, child-bearing desire of the second child is studied and analyzed. It is found that the two main factors have influenced people to make a choice of a second child birth. One of the two factors is the cost of bringing up a child, the other is child utility. This paper provides a basis for the study of the two-child family.
\end{abstract}

Keywords—child-bearing desire; two-child policy; child raising cost; child utility

\section{INTRODUCTION}

Since the late 1970s, Chinese "one child, one family" policy has lasted for several decades, this policy not only profoundly change every Chinese family life, also changed the course of the whole China's development. By carrying out family planning policy, less was born about a population of 400 million in China. It effectively alleviates the rapid population growth of social economic formation pressure. But, for a long time to control population growth, for the purpose of negative effects, as a result of the one-child policy has begun to highlight. And the continued population growth and aging which have made the national and population aging have presented to the development trend of aging, which caused a series of hindering the development of the social pension burden, only children education [1]. The shortage problems and contradictions also need to be addressed. Therefore, our country is a timely take measures to gradually let go two child policy, encourage couples to have qualified maternity second child, however, of these potential couples, in line with the second child birth condition at least one party to the one-child, after when they enter the baby age, willing to two births, what factors will affect the second child, these are all problems must be considered in the process of population policy adjustment, is also this article concerns and questions.

\section{THE BACKGROUND OF THE TWO-CHILD POLICY}

\section{A. The Labor Shortage}

Since our country executes family planning policy, after years of time, has accumulated more than 400 million people have fewer, greatly reduce the excessively rapid growth of population pressure on resources and environment, promote the economic and social development. However, China's total fertility rate has been below replacement level. According to the fifth and sixth census original data show that China's total fertility rate has been reduced. This shows that China's population growth in a decade has always been in the stage of low birth level. Related to this, our country has entered the aging population in the world, according to the sixth national population census data, China will enter the range of the oldest countries in the world, high population ageing will worse labor market economic and social development in China, the old-age social security and other fields have a profound impact. In this context, there is an urgent need to adjust the population policy of our country [2]. To that end, countries are beginning to adjust the one-child policy, the implementation of separate two new policies, the implementation of the new policy will be on economic and social development is of positive significance, but also should pay attention to the resulting social problems.

\section{B. The Imbalance of Age Structure of Population}

The implementation of Chinese one-child policy is not static according to the different historical period of population. The needs of the development of social economy are a dynamic process. Separate two-child policy is put forward, it is China's one child policy to adjust and perfect embodiment. Since the implementation of family planning policy, our country in the aspect of controlling the population quantity to promote economic and social development achievements is beyond doubt, but it is at the cost of China's population structure imbalance while in the meantime to fine-tune birth policy, but it is not big. The imbalance of population age structure and population aging degree has deepen and working age population is shrinking fast [3]. Data showed that if the current policy on birth control remains unchanged, the future of our country will face the situation of aging population scale is expanding fast and accelerated aging. If policy remains unchanged, the future of our country children's population would continue to fall, its direct consequence is the rapid decline of the total working-age population. This will bring some negative impact on China's economic sustainable development.

\section{The Imbalance of Sex Structure of Population}

The population sex structure imbalance, the sex ratio at birth in China along with the family planning policy strictly implement and constantly high, according to the Chinese official records of social sciences published, at present our country population sex ratio imbalance, China was the marriage age will be the number of men far more than women. Finally, family structure prominent changes have taken place in the process of policy implementation, ageing is accompanied by Jane, only child aging, the aging of empty nest, the Chinese family is the core and miniaturization. This family structure is more weaken the function of family endowment, indirectly, poses challenges to social endowment service [4]. In addition, 
the total fertility rate stability is reduced and the decline in fertility intentions, urban and rural residents in recent years also have contributed to embark on an important factor of fertility policy adjustment in China. Thus, major changes have taken place in the situation of population in China at the present stage. In order to promote the development of population and social long-term equilibrium, you need to make necessary adjustment to the current family planning policy [5].

\section{TWO THEORETICAL RESEARCH AND LITERATURE REVIEW}

\section{A. The Related International Theory}

In the last century, western developed countries population fertility falling caused many scholars research on the theory of fertility, it is first suggested in economics concepts and economic theory to explain family children cost and utility, and children cost microeconomics utility model was set up, the population of the west economics assumes that husband and wife is rational economic man in reproductive decisions using the utility, maximization principle, namely the reasonable use and allocation of limited resources to maximize family utility [6]. Lai bin that the child is costs include direct costs and indirect costs, direct costs for the child's life, education and entertainment expenses. Indirect costs for the parents to raise children in the education opportunities and job opportunity costs, such as the decrease of income, and the utility of children mainly divided into pleasure, utility economic utility and insurance.

Children bear the risk of family economic success or failure of utility, long-term to maintain family status, and extend the utility of family size. Lai bin's rational choice model of marginal children, namely through the second child of the cost and utility to compare and weigh the rational couple according to economic and social culture factors to consider, to decide whether to children [7]. When a family expected utility is greater than the expected cost of the second child, the parents will tend to have a second child, when the second child of the expected utility cost less than expected, parents might be inclined to give up the child's birth.

\section{B. The Theory Combined with Chinese Status}

It shows that there are no children than has been fathered a child of respondents prefer two births, and consistent in stratified analysis of different family type.

But one gender for second child birth will not have a significant impact, reflecting the boy preference significantly reduce the urban residents, may be the city social security level unceasing enhancement, weaken the birth boy and pension, a study conducted in Shanghai in 2008 also get the same conclusion.

Second child fertility intentions are greatly influenced by geography, in different parts of the different life stress, the level of economic and cultural background, family values also differ in thousands ways, these would be in a certain extent affect the respondents' willingness to second child birth [8].

Study conclusion shows that the cultural level has no impact on the willingness of one-child himself to breed, and, according to a study by $\mathrm{Xu}$ Yingmei, one-child family women of childbearing age birth two children will have a negative impact, which people pay more attention to personal development with higher education and the quality of life, so don't want to have more children. But in this study, two-child fertility intention is higher, the highest degree of culture or even become one of the biggest factors affect second child birth wishes, observed cultural degree and effect between twochild fertility intentions, to a certain extent, affected by the geographical factors [9].

To implement the party's twelve identified as one of our basic state policy of family planning, the family planning policy 30 years, significant changes have taken place in family structure in our country, the one-child family proportion rises year by year, also in the only-child increase year by year, a child of a family of faith is deeply rooted in the hearts of the people, even many only-child children I have another brother or sister to parents are strongly against it.

\section{The Literature Review}

After a rapidly after the transition from high fertility to low fertility, population in our country at present the main contradiction is no longer a fast population growth, but the demographic dividend disappears, birth sex ratio imbalance, an aging population, near the low fertility level, old before rich and so on." The central committee of the communist party of China on comprehensively deepen reform certain major issue decision", adhere to the basic state policy of family planning, the launch party is only children couples can have two child policy, gradually perfect fertility policy adjustment, promote the population long-term balanced development.

Nowadays, scholars both at home and abroad for family fertility behavior research mainly focused on the trend of childbearing willing, childbearing willing influence factors in different populations and willingness of business cost, in fertility intentions and influencing factors of research, with five major cities in China married youth survey data, the double alone the couple's second child fertility intentions and related influence factors are described and the comparative analysis, using research to obtain a sample for analysis, investigates the second child birth will influence factors of urban residents and regional differences [10].

Through the analysis of the questionnaires data, studying the effect of the economic level of fertility intentions, from the Angle of the order of birth decision-making behavior mode, to the rural one male and one female households' willingness to give birth to two dimensions in number and gender, and use the acquisition of three provinces in six fertility intentions survey data for the analysis of the affecting factors related. Use of population and family planning commission supports the data analysis of the factors affecting fertility intentions and the study found that education level and economic factors are the main influence factors. At the same time, the family endowment pressure also has a certain influence on fertility intentions. Based on fertility intentions survey conducted by the national data, analysis of China's urban and rural residents fertility intentions, a large number of scholars have mainly through the double alone family fertility intention questionnaire data analysis, to separate family second child birth intend to explore the influential factors, and combined with China's national conditions to design the cost scale and utility scale. 


\section{PROBLEMS}

Society is made up of people and no one is the existence of the society as a whole is gone. China is a populous country, so the population problem has always been a key issue in academic research. Appropriate population quantity and quality will promote the development of social productivity, and vice versa [7]. In order to make the population development and adapt to social and economic development, coordinated with resources and environment, our country implemented the onechild policy. Although the family planning policy implemented in recent 40 years, results proved good, but with the development of society and economy, the policy in the population has also brought us new problems and challenges.

Low fertility, population aging sharply, population sex ratio imbalance, the one-child population and the resulting a series of problems will affect Chinese long-term equilibrium development. For family planning policy has been adjusted, the policies of the newly revised rules "husband and wife or both of the parties as the only children allowed maternity second child. But the fertility level of a society as a whole is directly influenced by two factors: one is the state of one child policy the other is the willingness of people to breed. Although the domestic scholars on how the fertility policy adjustment and how to adjust the heated debate, but they just pay attention to the policy level and ignored the family as the main body of the willingness of people to breed.

The stand or fall of birth policy without fertility intention and behavior, so through the study of the second child birth fertility intentions and influence factors to formulate policy on birth control, to solve the population problem is very important.

Chinese family planning policy has produced many problems in the implementation process. The population structural contradiction in not only, more important is to control the population growth will be hard to achieve the goal of optimization of population structure, to reduce the sex ratio at birth. If you want to ease the population aging and the imbalance of sex ratio at birth problem, cannot be based on the control of population.

\section{SUMMARY}

Some families have intend to have two children, most of the families are still willing to respond to separate two-child policy, but the proportion of its proportion and not willing to two births don't vary that much. Therefore the cause of the baby boom may not be very big. The effects of economic factors on childbearing willing obviously are obviously the past for begat fertility motivation is different. Now in the cost of children, children and education costs are the main factors influencing the family planning choices. In the utility at the same time in children, the children can bring economic utility is the main factor of fertility choices. Visible now rising cost of living, children education costs soaring, makes a lot of families are reluctant to bear huge economic pressure, so don't want to have two children. In addition to economic factors on the twochild family influence, other non-economic factors effect is stronger. Among them, the career development pressure in the main cost factor, children education pressure energy and time factor performance significantly. After this also reflected the now, separate couple with professional ideals, freedom, and the characteristics of the concerns about children education.

\section{REFERENCES}

[1] World Bank. World Development Indicators. 2003

[2] Franco Modigliani. Life Cycle, Individual Thrift, and the Wealth of Nations. The American Economist. 1985

[3] Hoover E. Population Growth and Economic Development in Lowincome countries. 1958

[4] Kaufman Joan. Myths and Realities of Chinese Population Program. Harvard Asia Quarterly. 2003

[5] Arnold F, Z Liu. Sex Preference, Fertility and Family Planning in China. Population and Development Review. 1986

[6] Ehrlich P. The Population Bomb. 1968

[7] Leibenstein H. Economic Backwardness and Economic Growth. 1957

[8] United Nations. Long-range World Population Projections: Based on the 1998 Revision. Journal of Women s Health. 2000

[9] Becker Gary S. The Economic Approach to Human Behavior. 1976

[10] Simon Julian L. The Ultimate Resource. 1981 